\title{
Discharge of dissolved black carbon from a fire-affected intertidal system
}

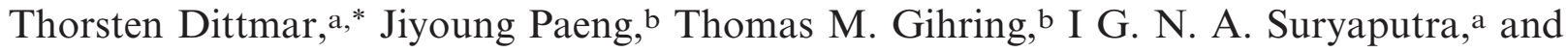 \\ Markus Huettel ${ }^{\mathrm{b}}$
}

${ }^{a}$ Max Planck Research Group for Marine Geochemistry, University of Oldenburg, Institute for Chemistry and Biology of the Marine Environment, Oldenburg, Germany

b Department of Earth, Ocean and Atmospheric Science, Florida State University, Florida

\begin{abstract}
We report substantial tidal fluxes of dissolved black carbon (DBC) in a fire-affected marsh in the northern Gulf of Mexico. DBC was molecularly determined as benzenepolycarboxylic acids in a tidal creek, adjacent rivers, and the coastal ocean. Supported by stable carbon isotope and in situ fluorescence measurements, three sources of dissolved organic carbon (DOC) were identified that mixed conservatively in the coastal system: groundwater from salt marshes, river water, and seawater. Groundwater was the main source of DBC to the creek. The highest DBC concentrations of up to $41 \mu \mathrm{mol} \mathrm{C} \mathrm{L}-1$ (7.2\% of DOC) were found in the creek at low tide, compared with $<$ $18 \mu \mathrm{mol} \mathrm{C} \mathrm{L}{ }^{-1}$ in all other samples. Over the studied tidal cycle, we determined a runoff (load per drainage area) of 3700 moles DBC (44 kg C) $\mathrm{km}^{-2}$ of salt marsh. This is high compared with the Apalachicola River, where the annual DBC runoff is on the order of $10^{4} \mathrm{~mol}(120 \mathrm{~kg} \mathrm{C}) \mathrm{km}^{-2} \mathrm{yr}^{-1}$. In the marsh, it would require $\sim 20$ tidal cycles similar to the one that we studied to remove all black carbon produced during one fire event. Because a spring tide was studied, our estimate is as an upper limit. DBC is ubiquitous in the global ocean, and dissolution and subsequent lateral transport appear to be important removal mechanisms for soil black carbon. Our study, which provides a snapshot in time and space, demonstrates that tidal fluxes may be primary carriers of DBC, and therefore tidal pumping and groundwater discharge cannot be ignored in assessing the continental runoff of $\mathrm{DBC}$.
\end{abstract}

The residues of biomass burning contain some of the most resistant organic compounds known on Earth's surface (Masiello 2004). Charred organic matter is often the only identifiable remnant of prehistoric human settlements (Cohen-Ofri et al. 2006), and virtually all soils and sediments contain charcoal or soot, a testimony of widespread wildfires over the past millennia (Masiello and Druffel 1998; Forbes et al. 2006). Pyrogenic organic matter (also known as black carbon) is more resistant to biomineralization compared with common biomolecules, and black carbon selectively accumulates in soils and sediments on time scales of decades and centuries (Forbes et al. 2006). In the long term, however, black carbon also decomposes, and after several millennia, only a fraction of the original pyrogenic matter is preserved in soils and sediments (Druffel 2004; Major et al. 2010). The molecular structure and stability of black carbon in the environment depends largely on the charring temperature, which can be highly variable in wildfires. Chars produced at low temperatures are less condensed and richer in polar functional groups than those produced at higher temperatures (Kuo et al. 2008; Keiluweit et al. 2010; Schneider et al. 2010). Low-temperature chars cycle on the order of decades to centuries (Alexis et al. 2007; Zimmerman 2010). Graphite-like structures, on the other hand, are one of the most resistant forms of reduced carbon on Earth (Dickens et al. 2004). In addition, environmental factors and soil physical properties determine the fate of black carbon in soils (Major et al. 2010). Due to the stability of black carbon in the environment, knowledge of the turnover mechanisms are crucial to our understanding of global

\footnotetext{
* Corresponding author: tdittmar@mpi-bremen.de
}

biogeochemical cycles. The production of black carbon has been proposed as a potential geoengineering tool to sequester carbon from active cycles (Lehmann et al. 2006). However, because the driving forces behind black carbon turnover are not well-understood, any geoengineering attempt involving black carbon could be a fruitless endeavor in the long term.

In addition to mineralization, lateral transport in the landscape can be a significant process for the removal of black carbon from soils (Mannino and Harvey 2004; Guggenberger et al. 2008; Major et al. 2010). Charcoal that is produced at high temperatures has a low solubility in water; however, after decades of microbial attack in soils, oxygen is introduced into the condensed aromatic structure of charcoal. The resulting carboxylated molecular subunits dissolve in water and can migrate through the soil (Hockaday et al. 2006; Cheng and Lehmann 2009). This process explains the presence of a pyrogenic component in dissolved organic matter (DOM) in streams and estuaries (Kim et al. 2004; Mannino and Harvey 2004; Guggenberger et al. 2008) that transport dissolved black carbon (DBC) to the ocean, where it is ubiquitous. Even in the most remote deep ocean basins, $\sim 2 \%$ of DOM has a heat-induced molecular structure (Dittmar and Koch 2006; Dittmar and Paeng 2009). Solubilization and subsequent transport in the dissolved form could be one of the main removal mechanisms of black carbon in soils. DBC is expected to be released slowly from soils over long periods after a fire event. It is therefore likely that water runoff, in addition to microbial oxidation, is a major controlling factor in the long-term release of black carbon from soils.

By far, the largest volume of water runoff on the continents occurs in the intertidal zone, whereas tidal 
flushing floods and drains large vegetated areas once or twice a day. Tidal exchange is so efficient that, in many coastal areas, the flux of organic matter from intertidal vegetated areas exceeds riverine fluxes (Dittmar et al. 2001). For example, $>10 \%$ of the worldwide land-ocean flux of DOM is derived from mangroves alone, even though this tropical intertidal biome covers only $0.1 \%$ of the land surface (Dittmar et al. 2006). Material transport from salt marshes, the dominant intertidal vegetation of subtropic and temperate climate zones, could be similarly efficient (Moran et al. 1991).

Here, we hypothesize that tidal fluxes can be a main carrier of DBC. To test this hypothesis, we investigated the tidal pattern of DOM and its pyrogenic (black carbon) component in a tidal creek and adjacent estuary of the Apalachicola River in the northeastern Gulf of Mexico. The intertidal marsh system was affected by a major burning event $3 \mathrm{yr}$ prior to the sampling campaign. Deposition of soil-derived black carbon particles from the riverine catchment area during past storm surges is another likely source of black carbon in the marsh. Otherwise, the system was in relatively pristine conditions. There are no major settlements or industries in the immediate vicinity, and no major oil spills were reported in the area for the past decades prior to our investigation. The Apalachicola River is Florida's largest river in terms of water discharge, and it drains $\sim 50,000 \mathrm{~km}^{2}$ (Edmiston 2008). Prescribed burning of large forested areas and marshes is a common management practice within the catchment. Therefore, it is reasonable to assume that the drainage areas of the studied tidal creek and rivers all contain a substantial standing stock of soil black carbon. The main goals of the study were to determine the pathways and to estimate the magnitude of DBC release from the marsh system to the ocean.

\section{Methods}

Sampling - Sampling was performed during a spring tide cycle on 04-05 June 2007 in the Apalachicola National Estuarine Research Reserve. A boat operated by the Reserve management team was used as an anchored working platform. The spring tide cycle was purposefully chosen because of the expected strong tidal flushing. During neap tides, the fluxes are largely driven by wind and are less predictable. The samples were collected from a tidal creek (Buzzard Bayou; 2945.793 N, 8459.625 W) that drains freshwater swamps and salt marshes and eventually links to the Little St. Marks River that splits off the Apalachicola River $\sim 15 \mathrm{~km}$ before the latter reaches Apalachicola Bay (Fig. 1). At the sampling station, the creek had a width of $25 \mathrm{~m}$ and a maximum depth of $2.25 \mathrm{~m}$ at high tide. The tidal range was $63 \mathrm{~cm}$ on the day of sampling. The creek starts in the salt marsh $\sim 1 \mathrm{~km}$ upstream of our sampling site, and it has no links to other creeks or rivers other than the connection to the Little St. Marks River. Minor sheet flow may temporarily link the creek to the nearby Little St. Marks and St. Marks rivers only during extreme high tides and major rain events. The tidal creek was sampled in its cross-sectional center, hourly over $25 \mathrm{~h}$ at $10 \mathrm{~cm}$ below the water surface and $\sim 60 \mathrm{~cm}$

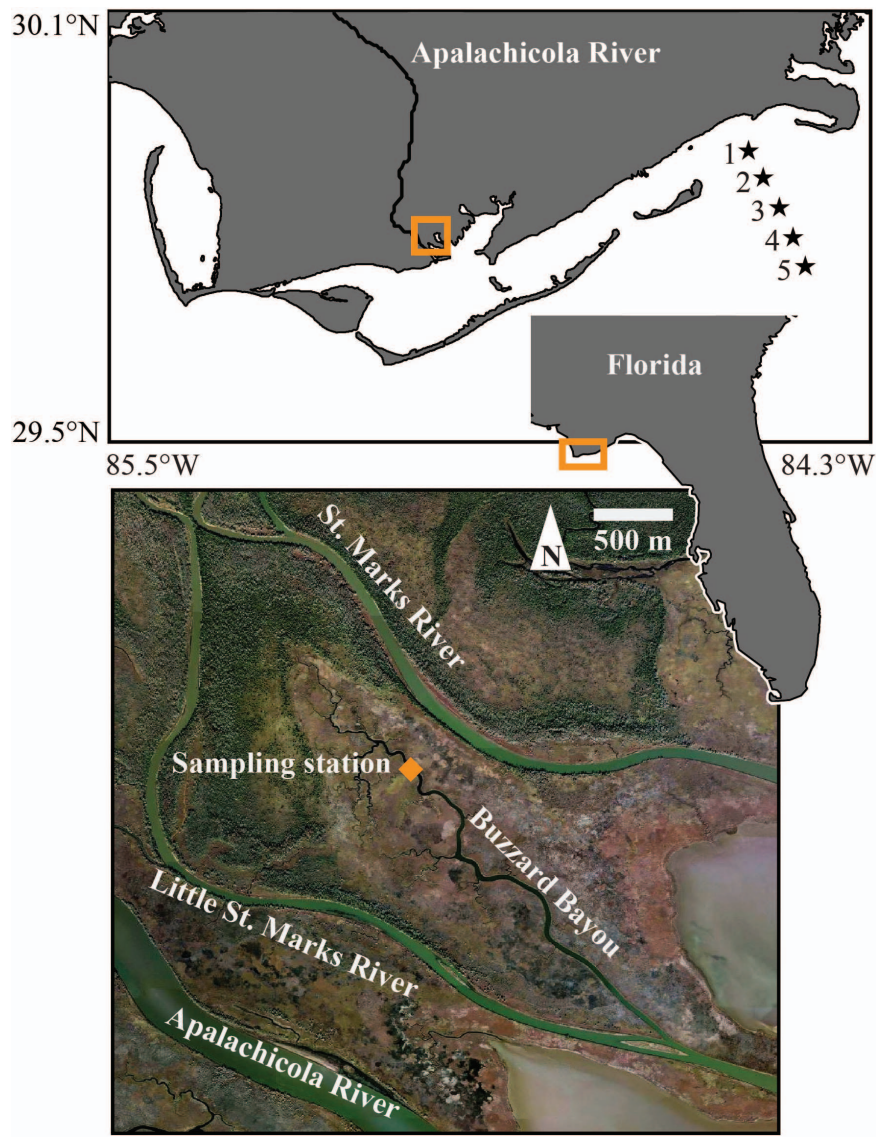

Fig. 1. The sampling area in the northern Gulf of Mexico. The satellite image was modified from www.bing.com. Numbers at the marine sampling stations refer to the results in Table 1.

above the bottom. The riverine endmembers (Little St. Marks River and Apalachicola River) were sampled at salinity between 1 and 2 during the ebb cycle of 05 June 2007. A salinity of $>0$ was purposefully chosen for endmember sampling to account for the potential physicochemical influence of salinity on the DOM composition and concentration. Samples were drawn with a peristaltic pump through acid-rinsed polyethylene tubing and in-line Whatman glass-fiber filters $(\mathrm{GF} / \mathrm{F})$ into precombusted glass bottles. The marine endmember was sampled on 13 June 2007 at five stations along an offshore transect east of Apalachicola Bay during a cruise aboard R/V Seminole. Samples were taken at $0.5 \mathrm{~m}$ below the sea surface and $1 \mathrm{~m}$ above the seafloor using a Niskin sampler. Samples were vacuum-filtered through Whatman GF/F filters into glass bottles. After filtration, all samples were immediately acidified with $\mathrm{HCl}$ (10 molar, analytical grade) to $\mathrm{pH}=2$.

In situ measurements-To characterize the temporal changes in the creek water associated with the change of the tides, several parameters were monitored at 2-min intervals. An in situ fluorometer (Wetlabs ECO Triplet) that recorded the concentration of chromophoric DOM $(\mathrm{CDOM})$, using fluorescence measurements (Excitation: $370 \mathrm{~nm}$, Emission: $460 \mathrm{~nm}$ ) was anchored next to the inlet of the sampling tubing at $\sim 60 \mathrm{~cm}$ above creek bottom. In 
addition, chlorophyll $a(\mathrm{Chl} a)$ fluorescence (Excitation: $470 \mathrm{~nm}$, Emission: $695 \mathrm{~nm}$ ) and turbidity (light-scattering of $660 \mathrm{~nm}$ ) were monitored by the same instrument. The sensor was calibrated by the manufacturer. CDOM concentrations are expressed as quinine sulfate equivalents (QSE, $\mathrm{m} \mathrm{L}^{-1}$ ). Salinity (calculated from the measured conductivity) and temperature were recorded using an in situ sensor (Sea Bird SBE 16) at the same depth and location as the other sensors. The water level of the tidal creek was manually recorded every 15 min using a fixed scale at the margin of the creek. The current direction was manually determined at the two sampling depths using floating objects (creek surface) and submerged discs (subsurface). In addition, vertical profiles of current direction and flow velocity were determined by lowering an acoustic Doppler velocimeter (Nortek Vector ADV) through the water column of the creek. The velocimeter was lowered at 5-min intervals during periods of strongest tidal currents and at 30-min intervals during stagnating tides.

To estimate water flux, the water column was divided into two compartments: the surface layer $(0-50 \mathrm{~cm})$, and the subsurface $(>50 \mathrm{~cm})$. The water velocities measured with the acoustic Doppler velocimeter were averaged over the respective depth interval for each time point. The crosssectional area of the creek was measured once using a gauge at a $1-\mathrm{m}$ horizontal resolution and was recalculated for each time point based on the measured water depths. The water flux was obtained for each time point and depth compartment by multiplying the respective values for water velocity and cross-sectional area. The loads of DBC, dissolved organic carbon (DOC), and salt were estimated by multiplying the respective concentrations by the water flux. Concentrations were linearly interpolated between the hourly time points to obtain the same temporal resolution as the current velocity data.

Dissolved organic carbon-DOC was determined using a total organic carbon analyzer (Shimadzu TOC-VCPH). The analytical accuracy was tested daily against deep Atlantic seawater reference material and low-carbon water provided by the consensus reference materials program (D.A. Hansell, University of Miami, Florida). Procedural blanks, including the filtration step, were obtained using ultrapure water. These blank samples did not contain any detectable amounts of DOC. The detection limit for DOC was $5 \mu \mathrm{mol} \mathrm{L}^{-1}$, and the analytical accuracy (relative to the reference material) and precision (replicate injections) were within $\pm 1 \mu \mathrm{mol} \mathrm{L}-1$.

Dissolved black carbon ( $D B C$ )-For the determination of black carbon, a wide range of different analytical methods currently exist, each addressing a different spectrum of the black carbon continuum (Hammes et al. 2007). In this study, DBC was determined at the molecular level via the benzenepolycarboxylic acid (BPCA) method (Dittmar 2008). This method is the most sensitive and unambiguous method for the determination of black carbon in marine DOM. It was originally developed for coal and soil analyses (Glaser et al. 1998; Brodowski et al. 2005; Kawamura et al. 2006) and later modified for the analysis of DOM (Dittmar
2008). This method specifically quantifies condensed aromatic moieties, and black carbon-free biomass from algae and vascular plants does not yield detectable amounts of BPCAs (Dittmar 2008). Furthermore, the relative proportion of the eight different detectable BPCAs is indicative of the extent of condensation and size of the polycyclic aromates (e.g., char produced at $200^{\circ} \mathrm{C}$ is characterized by BPCAs with a low number of carboxylic groups, whereas biomass charred at $1000^{\circ} \mathrm{C}$ mainly yields benzenehexacarboxylic acid [Schneider et al. 2010]).

Prior to molecular analysis, DOM was isolated from the water samples via solid-phase extraction (Dittmar et al. 2008). One liter of filtered water was acidified with $\mathrm{HCl}$ (10 molar, analytical grade) to $\mathrm{pH}=2$ and passed via gravity through solid-phase cartridges (Varian Bond Elut PPL, $1 \mathrm{~g}$ ). The cartridges were desalted with $0.01 \mathrm{~mol} \mathrm{~L}^{-1} \mathrm{HCl}$, dried with a stream of $\mathrm{N}_{2}$, and DOM was eluted with $6 \mathrm{~mL}$ of methanol (analytical grade). The DOC extraction efficiency was determined for each sample after evaporating an aliquot of the methanol extract to dryness, redissolving it in ultrapure water, and determining the DOC concentration in this solution. The ratio between extracted and total DOC concentrations is considered the extraction efficiency. On average among all samples $(n=74), 65 \%$ (SE $\pm 1.8 \%$ ) of the DOC could be recovered by the solid-phase extraction.

For BPCA analysis, $1 \mathrm{~mL}$ of the methanol extracts were transferred into 2-mL glass ampoules, evaporated to dryness under a $\mathrm{N}_{2}$ stream, and redissolved in $0.5 \mathrm{~mL}$ of $\mathrm{HNO}_{3}$ $(65 \%)$. The ampoules were then sealed, placed in a stainlesssteel pressure bomb, and kept for $9 \mathrm{~h}$ at $170^{\circ} \mathrm{C}$ in a furnace. After the ampoules had cooled, the nitric acid was evaporated in a heating block at $50^{\circ} \mathrm{C}$ under a stream of $\mathrm{N}_{2}$. The samples were redissolved in $250 \mu \mathrm{L}$ of ultrapure water, and aliquots were transferred into high-performance liquid chromatography system (HPLC) autosampler vials. The recovery of BPCAs was complete during all analytical steps, including oxidation, as determined using a BPCA standard solution (for details see Dittmar 2008). BPCAs were determined on a Shimadzu HPLC (10ADvp) equipped with an autosampler, sample and column coolers, and a photodiode-array light absorbance detector (RF-10AXL). BPCAs were separated on a Waters Sunfire C18 column $(2.1 \times 150 \mathrm{~mm}, 3.5 \mu \mathrm{m})$ using an aqueous-phase methanol gradient, as described by Dittmar (2008). The aqueous phase consisted of a tetrabutylammonium bromide solution $(4 \mathrm{mmol} \mathrm{L}-1)$ and sodium acetate $\left(50 \mathrm{mmol} \mathrm{L}^{-1}\right)$. The injection volume was $4 \mu \mathrm{L}$. BPCAs were identified according to retention time and absorbance spectra $(220-380 \mathrm{~nm})$. Quantification was performed using the absorbance signal at $240 \mathrm{~nm}$ and an external calibration. Benzenetricarboxylic acids (1,2,3-, 1,2,4-, 1,3,5-B3CA), benzenetetracarboxylic acids $(1,2,4,5-, 1,2,3,4-$ and 1,2,3,5-B4CA), benzenepentacarboxylic acid (B5CA), and benzenehexacarboxylic acid (B6CA) were determined.

The concentration of $\mathrm{DBC}\left(\mathrm{mol}\right.$ carbon $\mathrm{L}^{-1}$ ) was calculated based on the concentrations of the individual BPCAs (mol phenol L-1) after Dittmar (2008): DBC = $33.4 \times(\mathrm{B} 6 \mathrm{CA}+\mathrm{B} 5 \mathrm{CA}+0.5 \mathrm{~B} 4 \mathrm{CA}+0.5 \mathrm{~B} 3 \mathrm{CA})$. This formula is based on proposed structures for DBC (Dittmar 2008). 


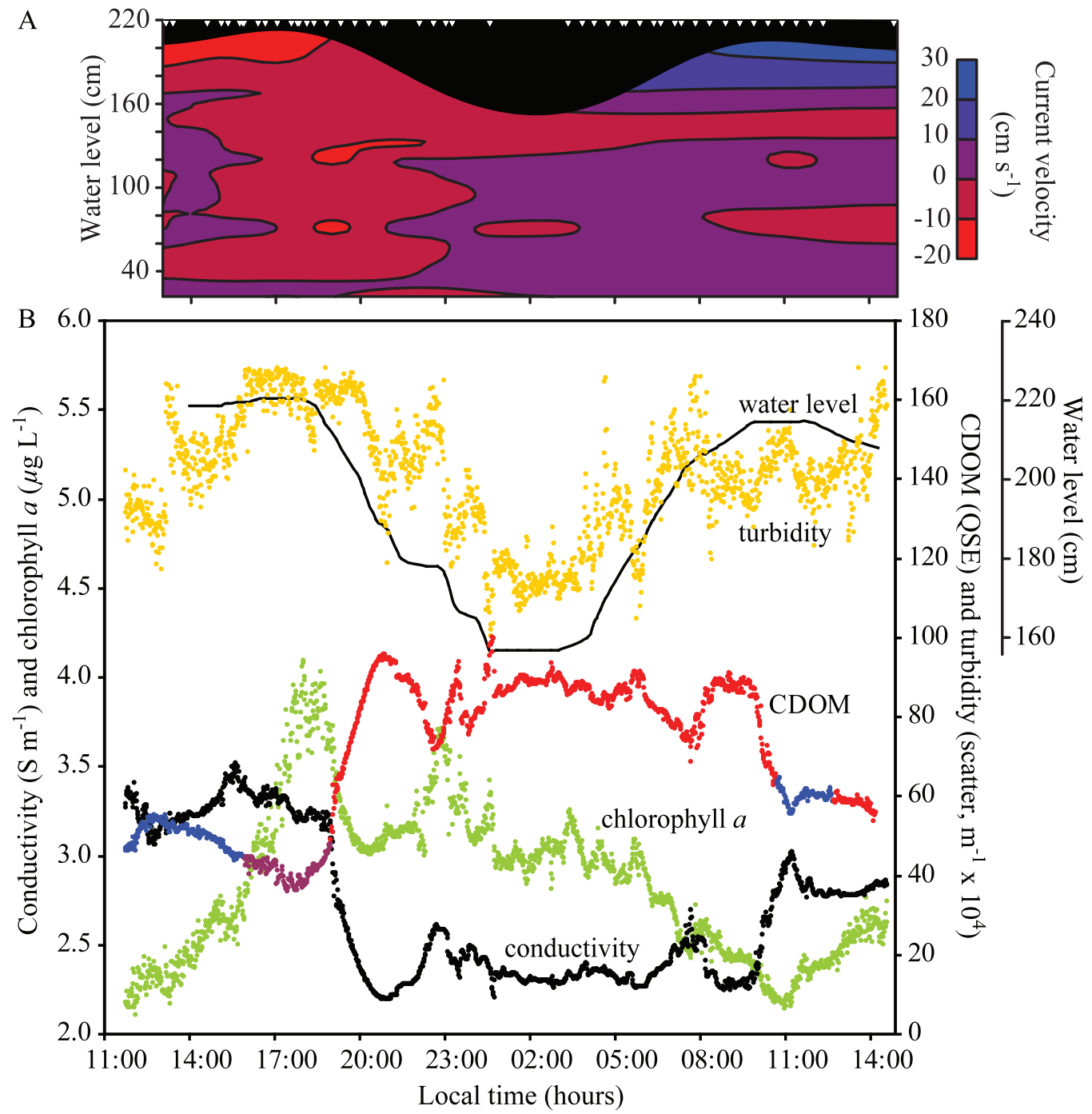

Fig. 2. Time series of in situ measurements in the tidal creek. All sensors were located close to the middle of the creek. (A) The current profile was obtained with help of an acoustic Doppler velocimeter (ADV). White triangles on top indicate time points of ADV deployment. Red colors indicate water currents toward Apalachicola Bay, and blue colors indicate water currents from the Bay into the marsh. The maximum deployment depth of the ADV was $60 \mathrm{~cm}$ above ground, a depth similar to where the other in situ sensors were anchored. (B) Chromophoric dissolved organic matter (CDOM) data are color-coded according to the flow direction obtained from the manual measurements at the sampling points: blue indicates incoming tide; red indicates outflowing tide; and purple shows stagnating tide.

Stable carbon isotopes-To obtain information on the sources of the extracted DOM, the stable carbon isotope composition of the solid-phase-extracted DOM was determined. For this purpose, methanol extracts containing $\sim 20 \mu \mathrm{g}$ of DOC were pipetted into $\mathrm{Zn}$ caps and dried in an oven at $50^{\circ} \mathrm{C}$. The $\mathrm{Zn}$ caps were then closed and analyzed on a Thermo Delta isotope-ratio mass spectrometer equipped with a high-temperature combustion unit at the National High Magnetic Field Laboratory (Tallahassee, Florida). Stable carbon isotope ratios are expressed as $\delta^{13} \mathrm{C}$ relative to the PDB reference. Procedural blanks did not yield detectable amounts of carbon isotopes.

Statistical analysis-All statistical data given here are based on a Pearson correlation analysis and geometric mean regression that were performed after confirming a normal distribution of the data. Average values were compared using a Student's $t$-test. The software program SigmaPlot 10.0 was used for all statistical analysis.

Results

The water level showed a sinusoidal pattern with a tidal range of $\sim 0.6 \mathrm{~m}$ (Fig. 2). The current regime in the creek channel was complex. Pronounced countercurrents were observed mainly before and after the second high tide, with strong inflowing currents in the surface layer and outflowing currents in the subsurface layer. All detected water properties showed a clear tidal signature (Figs. 2, 3). The salinity and turbidity decreased during ebb and increased during flood, with highest values at high tide and lowest values at low tide. Salinity ranged between 6.8 and 21.5 in 


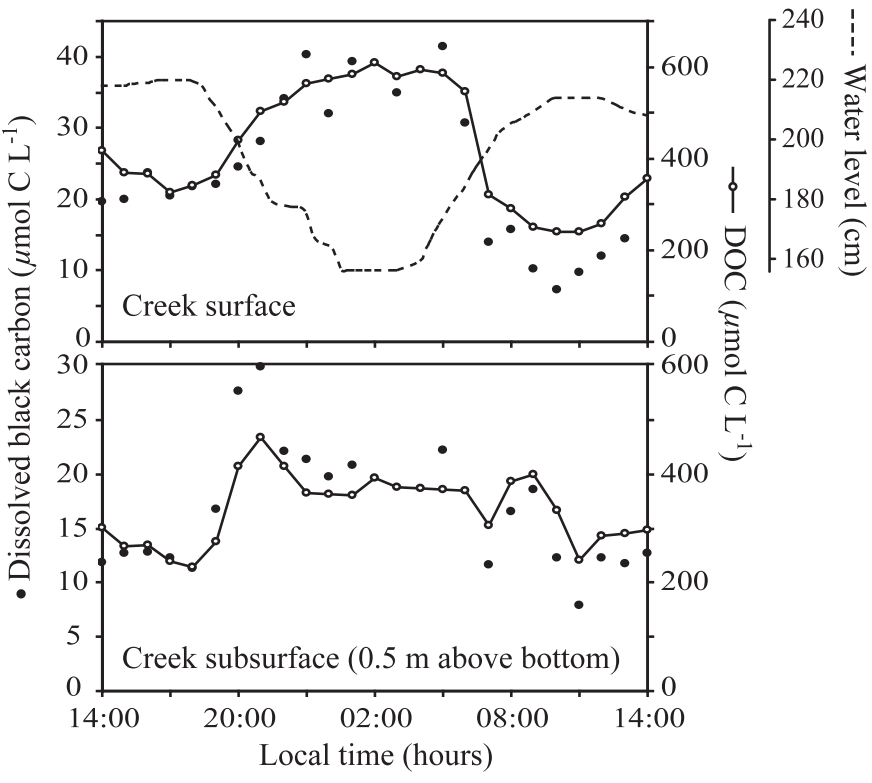

Fig. 3. Time series of dissolved black carbon and bulk dissolved organic carbon in the tidal creek in addition to the water level.

the creek. DOC, CDOM, and DBC showed an opposite trend than salinity and exhibited the highest concentrations at low tide. DOC concentrations ranged between $229 \mu \mathrm{mol} \mathrm{L}^{-1}$ and $608 \mu \mathrm{mol} \mathrm{L}^{-1}$, and the concentration of DBC ranged between $7 \mu \mathrm{mol} \mathrm{L}^{-1}$ and $41 \mu \mathrm{mol} \mathrm{L}^{-1}$ in the tidal creek (Fig. 3). The majority of the waterbody of the tidal creek was stratified with respect to all of the aforementioned parameters. The surface layer was generally characterized by lower salinity and higher concentrations of DOC, CDOM, and DBC compared with the subsurface. Stable carbon isotope ratios $\left(\delta^{13} \mathrm{C}\right)$ of DOM ranged between $-27.8 \%$ and $-26.2 \%$ in the tidal creek. The highest concentration of $\mathrm{Chl} a\left(4.1 \mu \mathrm{g} \mathrm{L}^{-1}\right)$ was observed during the first high tide in the afternoon, when the waterbody was stagnating, whereas the lowest concentrations $\left(2.1 \mu \mathrm{g} \mathrm{L}^{-1}\right)$ occurred immediately prior to high tide in the mornings of both sampling days.

One half tidal cycle (ebb or flood) carried an average of $5.8 \times 10^{5} \mathrm{~m}^{3}$ water. The flood tide carried $14 \%$ more water than the ebb tide, thereby resulting in a residual tidal flux of water into the marsh of $7.8 \times 10^{4} \mathrm{~m}^{3}$. In the surface layer, there was a residual tidal flux into the marsh $(9.8 \times$ $10^{4} \mathrm{~m}^{3}$ ), whereas there was a residual tidal flux out of the marsh $\left(-2.0 \times 10^{4} \mathrm{~m}^{3}\right)$ in the subsurface layer. In contrast to the water fluxes, the ebb tide carried $25 \%$ more DBC than the flood tide, thereby resulting in a residual tidal flux of $-3.0 \times 10^{3}$ moles DBC out of the marsh. There was a consistent residual tidal flux of $\mathrm{DBC}$ out of the marsh in both the creek surface $\left(-1.2 \times 10^{3}\right.$ moles $)$ and subsurface layers $\left(-1.8 \times 10^{3}\right.$ moles $)$. The residual tidal fluxes of DOC and salt were small in comparison (i.e., the respective fluxes of the ebb and flood cycles differed by $<10 \%$ ).

The DOC concentrations in Apalachicola River and Little St. Marks River were $224 \mu \mathrm{mol} \mathrm{L}{ }^{-1}$ and $206 \mu \mathrm{mol} \mathrm{L}^{-1}$, respectively. The concentration of DBC was $18.1 \mu \mathrm{mol} \mathrm{L}^{-1}$ in the Apalachicola River and $6.6 \mu \mathrm{mol} \mathrm{L}^{-1}$ in the Little St.
Marks River. Along the offshore transect, the DOC concentrations decreased from $116 \mu \mathrm{mol} \mathrm{L}^{-1}$ near shore to $88 \mu \mathrm{mol} \mathrm{L} \mathrm{L}^{-1}$ offshore, while the $\mathrm{DBC}$ concentrations decreased from $2.9 \mu \mathrm{mol} \mathrm{L}-1$ to $0.6 \mu \mathrm{mol} \mathrm{L}^{-1}$. Salinity increased along the transect from 35.4 to 36.5.

\section{Discussion}

The tidal pattern of the water properties (Figs. 2, 3) indicates the inflow of freshwater and DBC into the creek during ebb. The studied tidal creek has no direct aboveground connection to a river, and this inflow of freshwater is therefore due to groundwater discharge into the creek. The creek is enclosed by two river arms (Little St. Marks River and St. Marks River) that bifurcate from the same source connecting to the Apalachicola River (Fig. 1). Fresh groundwater in the creek is thus most likely derived from the nearby river arms that surround the catchment area of the creek and not from long-distance transport of fresh groundwater toward the creek. During its passage through the sediments, the fresh groundwater mixes with estuarine waters and discharges into the creek at low tide. A simplest scenario would be a conservative behavior of water properties during mixing in the sediments. However, a mixing model with a riverine (DOC: $215 \mu \mathrm{mol} \mathrm{L}^{-1}$ ) and marine endmember $(95 \mu \mathrm{mol} \mathrm{L}-1)$ did not account for the observed concentrations of DOC in the creek (Fig. 4). At brackish salinity conditions in the creek, DOC concentrations were $>600 \mu \mathrm{mol} \mathrm{L}^{-1}$. Similarly, DBC concentrations in the riverine and marine endmembers were $<18 \mu \mathrm{mol} \mathrm{L}^{-1}$, whereas concentrations of up to $41 \mu \mathrm{mol} \mathrm{L}-1$ occurred in the creek. Consequently, a considerable amount of DOC and $\mathrm{DBC}$ was added to the groundwater during its passage through the sediments and before it was discharged into the creek.

In situ production within the creek may also release DOC to the water column during low tide conditions, although this explanation can largely be ruled out based on in situ fluorescence measurements. CDOM and DOC concentrations were highly significantly correlated $(p<$ $0.001, r=0.92, n=25$ ), and DOC concentrations could be predicted from CDOM concentrations with help of a quadratic mean regression $(\mathrm{DOC}=4.80 \times \mathrm{CDOM}$; $\mathrm{SE}$ of slope: 0.33 ). The Chl $a$ and DOM parameters were largely uncoupled. In contrast to DOM, Chl $a$ was mainly controlled by the current velocity and time of day and was probably transported with estuarine waters into the creek, or washed off creek banks during high tide. The highest concentration of Chl $a$ was observed during high tide in the afternoon, when the waterbody was stagnating. Most remarkably, the minimum concentrations of CDOM and DOC coincided with this Chl $a$ maximum. This uncoupling between Chl $a$ and DOM shows that DOM was not primarily produced in the water column but was transported from an allochthonous source into the creek. This observation is consistent with the fact that DBC and bulk DOC exhibited synchronous tidal fluctuations with a maximum at low tide.

Turbidity may have interfered with the fluorescence measurements of CDOM and Chl $a$ by shading of the 




Surface $\Delta$ flood (DOC)

$\triangle \mathrm{ebb}(\mathrm{DOC})$

○ ebb (DOC, DOC*)

- stagnating tide (DOC, DOC*)

$\Delta$ riverine and marine endmembers

Fig. 4. Mixing diagram for dissolved organic carbon. DOC* are concentrations calculated from in situ fluorescence data (details are provided in the main text). DOC* is color-coded in accordance with Fig. 2.

detector cell. However, total suspended-solid concentrations were consistently $<10 \mathrm{mg} \mathrm{L}^{-1}$, as indicated by the level of red-light scatter (Boss et al. 2009). At this concentration of particles, interference with fluorescence detection is not expected (Saraceno et al. 2009). The turbidity readings indicated a higher colloidal load in the inflowing estuarine water than in the groundwater, with only minor resuspension and settling of particles.

A closer analysis of the mixing pattern indicates a complex, but apparently conservative, mixing of three DOC sources in the tidal creek (Fig. 4). During flood, there was a flux of freshwater into the creek in the surface layer and a flux of seawater in the subsurface layer. Both waterbodies had low DOC concentrations, and during flood they were well-separated and conservatively mixed in the creek with brackish water (high DOC concentrations). During the ebb cycle, brackish water with high DOC concentrations mixed conservatively with the fresh and marine water that had previously entered the creek.

Conservative properties of DOM in the system were also apparent on a compositional level. Independent of the time point and depth of sampling, the bulk DOC and DBC in the tidal creek were highly significantly $(p<0.001)$ correlated (Fig. 5). At high tide, $3.2 \%$ of DOC was DBC, which was the same value as in the Little St. Marks River. At low tide, DBC increased to $7.2 \%$ of the bulk DOC. All other values can be explained as a conservative mixture of low-tide and high-tide waters. If the regression (DOC vs. DBC; Fig. 5) is extrapolated to infinite concentrations of DOC and DBC, then the proportion of DBC to DOC (i.e., the reciprocal of the slope shown in Fig. 5) reaches $8.1 \%$ ( \pm $0.3 \mathrm{SE}$ ). Therefore, it can be concluded that DOC in the brackish groundwater that discharges into the tidal creek contained 7.2-8.1\% DBC.

In Apalachicola River, a similar proportion of DBC $(8.1 \%)$ was found. Interestingly, a similar ratio between DOC and DBC was also determined via the BPCA method in a river that drained a tundra ecotone in Northern Siberia (Guggenberger et al. 2008; and by using the BPCA-black carbon conversation equation of Dittmar 2008). Because of the comparatively high concentrations of DBC in the creek, Apalachicola River water must be excluded as the main 


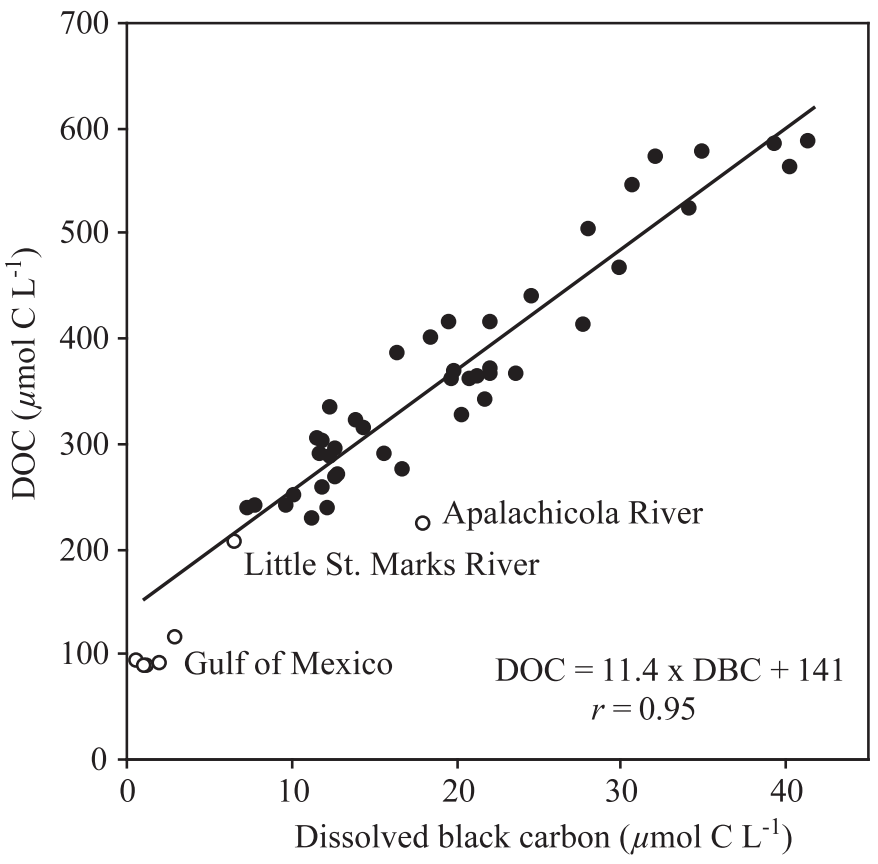

Fig. 5. Dissolved black carbon vs. bulk dissolved organic carbon. The regression data are derived from geometric mean regression analyses. Only samples from the tidal creek (black dots) were considered for the regression.

source of DBC in the creek. However, similar bodies of groundwater (in terms of DOC and DBC concentrations) may be the source of DBC to both the river and creek. In accordance with this observation, the composition of $\mathrm{DBC}$, as indicated by the relative proportion of the individual BPCAs, also did not exhibit significant differences between

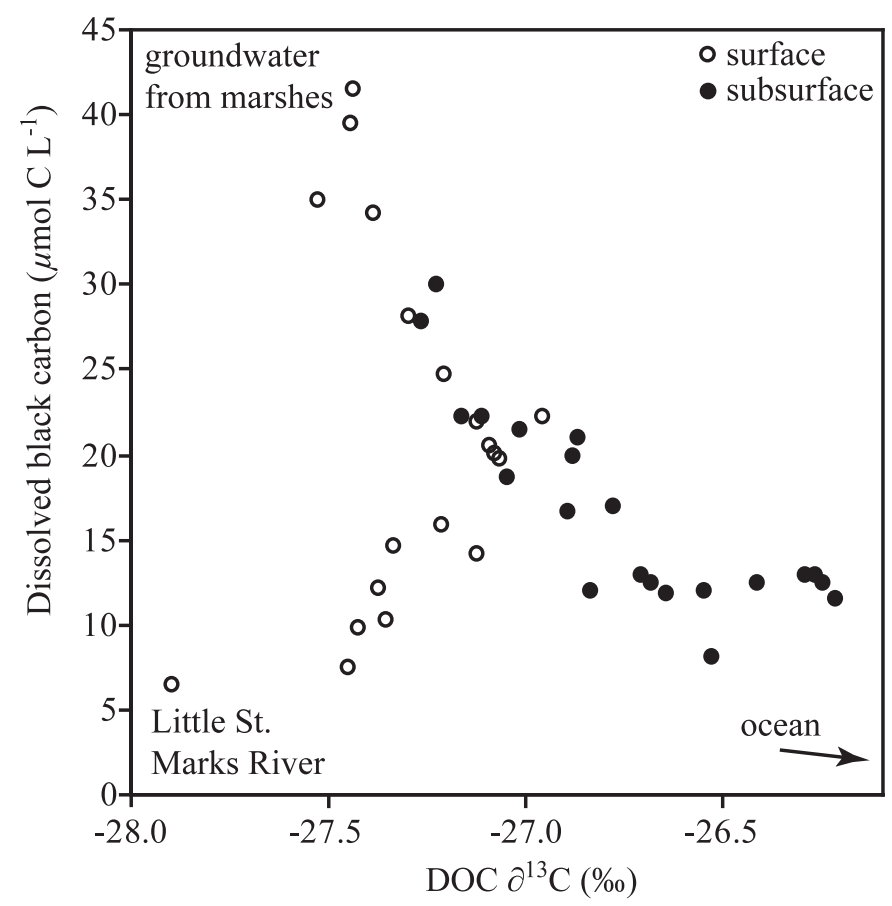

Fig. 6. Stable carbon isotope ratios of dissolved organic carbon vs. concentrations of dissolved black carbon. river and creek. The relative proportion of individual BPCAs is a measure of the molecular size of the DBC. A greater number of carboxylic groups of a given BPCA correspond to a larger original molecule. The predominant BPCAs were B4CAs (43\%, on average), followed by B5CA $(31 \%), \mathrm{B} 3 \mathrm{CA}(15 \%)$, and $\mathrm{B} 6 \mathrm{CA}(11 \%)$. The relative proportion of the individual BPCAs is consistent with published BPCA data for coastal waters (Dittmar 2008). Similar proportions of the individual BPCAs were also found in the water-soluble fraction of wood char that was aged for $10 \mathrm{yr}$ in a soil, whereas the water-soluble fraction of freshly produced wood char contained mainly B3CA and small amounts of B4CA (Abiven et al. 2011).

The stable carbon isotope composition of DOM has proven useful for the elucidation of the sources of organic matter in coastal areas (Dittmar et al. 2009). In the studied system, there are four major sources of organic matter that have distinct isotopic signatures (the following reference values are from Dittmar et al. 2009). The catchment area of the Apalachicola River is dominated by plants with the $\mathrm{C} 3$ photosynthetic mechanism, and thus $\delta^{13} \mathrm{C}$ values of $\sim-28 \%$ are expected for riverine DOM. The Little St. Marks River and the tidal creek drain freshwater marshes $\left(\delta^{13} \mathrm{C} \approx-14 \%\right)$ and salt marshes $\left(\delta^{13} \mathrm{C} \approx-28 \%\right.$ ). In situ production in Apalachicola Bay and the coastal zone is dominated by algae $\left(\delta^{13} \mathrm{C} \approx-21 \%\right.$, or lower, depending on the isotopic value of the inorganic carbon source) and sea grasses $\left(\delta^{13} \mathrm{C} \approx-11 \%\right)$. The measured stable carbon isotope ratios, in combination with DBC concentrations, indicate the mixing of three endmembers in the tidal creek (Fig. 6): (1) DOM derived from salt marshes; (2) riverine DOM; and (3) marine DOM. Water from the marshes had the highest concentrations of $\mathrm{DBC}$, whereas the river and marine endmember waters had relatively low black carbon concentrations. These observations confirm the results from the DOC mixing-model approach where salinity was used as a conservative tracer (Fig. 4). Despite the presence of C4 vegetation in freshwater marshes (Spartina grasses) in the catchment of the Little St. Marks River and the tidal creek, C4 plants did not have a significant imprint on the isotopic composition of DOM. We estimated the marine DOM component for each sample using the $\delta^{13} \mathrm{C}$ values of Little St. Marks River $(-27.9 \%)$ and the marine samples $(-22.4 \%)$ as endmembers. The contributions of marine DOC to the total DOC were $7-16 \%$ and $11-31 \%$ in the creek surface and subsurface layers, respectively, which is consistent with the observed salinity stratification.

DBC may survive offshore transport and be distributed over large scales, as indicated by a significant correlation between salinity and DBC for the Gulf of Mexico samples $(p<0.001, n=10)$. Here, surface and subsurface concentrations were not statistically different. For the same set of samples, bulk DOC and salinity were only weakly correlated $(p<0.05)$, thereby indicating a more dynamic behavior of bulk DOC compared with DBC. The theoretical freshwater endmember in the Gulf of Mexico was calculated based on a linear regression analysis between DBC and salinity. The theoretical freshwater endmember contained $>$ $38 \mu \mathrm{mol} \mathrm{L}-1$ of DBC with a probability of $p>0.95$. The concentration of DBC in the Apalachicola River, which is by 


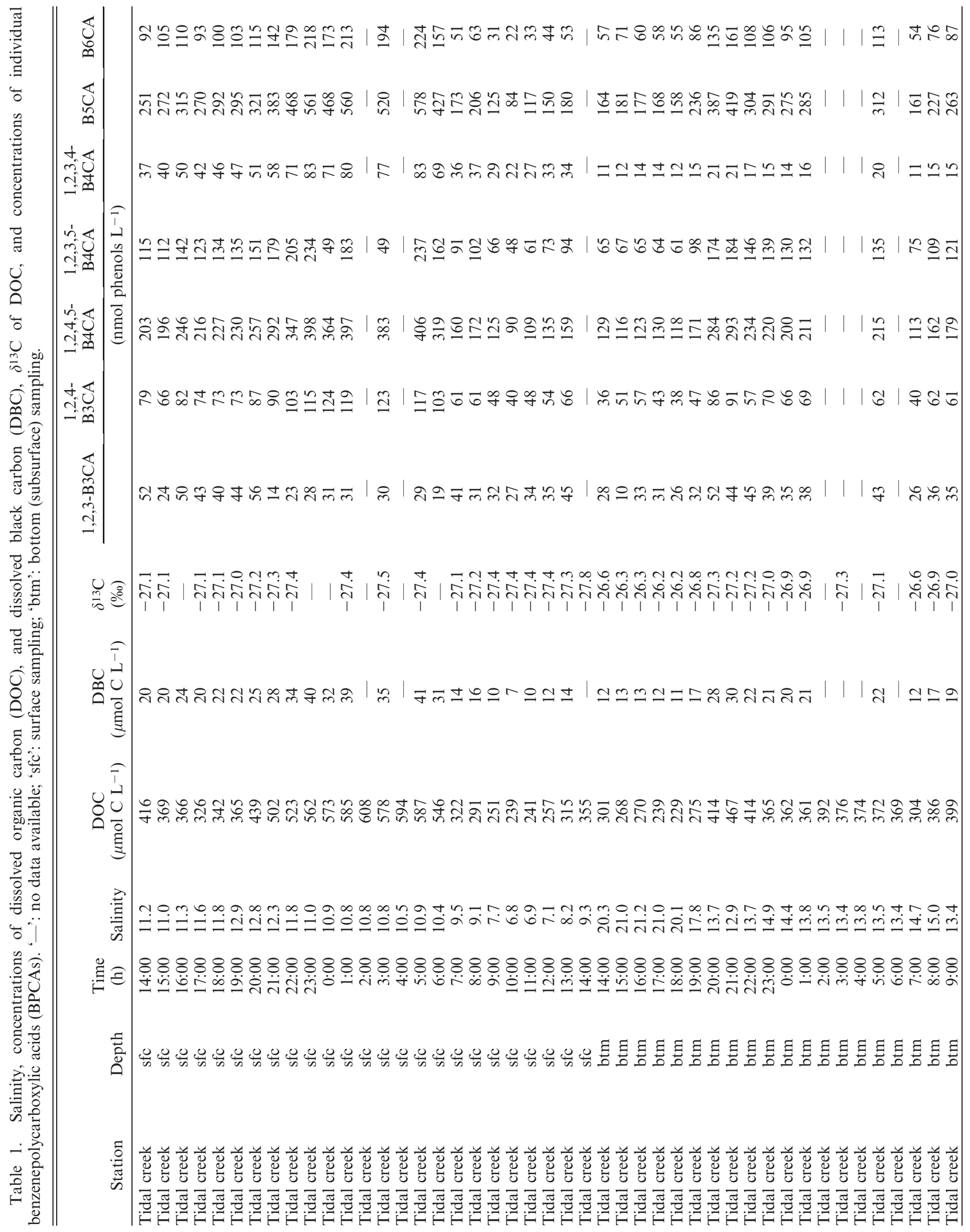






far the largest river in the region, was only $18.1 \mu \mathrm{mol} \mathrm{L}-1$. The reasons behind this discrepancy remain speculative. One explanation would be the presence of a major brackish water source of $\mathrm{DBC}$ in the region. The region east of the sampling area, Apalachee Bay, hosts one of the largest tidal marshes in the Gulf of Mexico. These extensive marshes in Apalachee Bay are subject to frequent burning (www.fws. gov/saintmarks/fire.html), and an extraordinarily large black carbon component has been observed in DOM from this bay compared with adjacent open waters (Dittmar 2008). Outwelling of DBC from Apalachee Bay marshes is therefore a possible explanation for the observed pattern in the offshore transect sampled in this study. Alternatively, the Apalachicola River may exhibit higher concentrations of $\mathrm{DBC}$ during other seasons than sampled here, or DBC may slowly degrade in the open ocean (e.g., by photochemical reactions), which could also cause an apparent increase of the theoretical freshwater endmember.

For a first rough estimate of the load (discharge per drainage area) of DBC in the Apalachicola River, we assume that our single time-point measurement is representative for a full year. Given the event-driven nature of river load, such an estimate is expected to provide an order of magnitude resolution. The annual average water runoff of the Apalachicola River is $690 \mathrm{~L} \mathrm{~m}^{-2} \mathrm{yr}^{-1}$ (Edmiston 2008), resulting in a runoff of DBC of $1.25 \times 10^{4} \mathrm{~mol} \mathrm{~km}^{-2} \mathrm{yr}^{-1}$. Although the margin of error of this estimate is unknown, it illustrates that only a fraction of the annual black carbon production is actually exported in the dissolved form. According to Alexis et al. (2007), one fire event in a Floridian oak scrub produces $\sim 5.6 \times 10^{6} \mathrm{~mol} \mathrm{~km}^{-2}$ of recalcitrant soil black carbon. If we assume a prescribed fire-return cycle of $11 \mathrm{yr}$ (Alexis et al. 2007) and an area of burning of $>20,000 \mathrm{~km}^{2}$ (estimate based on land cover; Edmiston 2008), the production rate of recalcitrant soil black carbon is $>2 \times 10^{5} \mathrm{~mol} \mathrm{~km} \mathrm{~km}^{-2} \mathrm{yr}^{-1}$ in the catchment of the Apalachicola River. Our estimates of the DBC runoff are two orders of magnitude higher than those determine for a field experiment in a savannah soil (Major et al. 2010), where $<0.04 \%$ of experimentally added charcoal was released as DOM in the course of $2 \mathrm{yr}$. The observed higher runoff in Florida could be explained, first, by an increase of the soluble fraction of black carbon in the course of decadal-scale microbial degradation (Hockaday et al. 2007), and, second, by a higher precipitation and water runoff in Florida compared with the savannah biome.

Over the studied tidal cycle, the runoff from the marsh system (residual tidal flux per drainage area) greatly exceeded the runoff from the riverine drainage area. Over the tidal cycle, we determined a residual tidal flux of DBC of $-3.0 \times 10^{3}$ moles out of the marsh. This residual tidal flux is the consequence of a considerable tidal asymmetry because the ebb cycle carried $25 \%$ more DBC than the flood cycle. This imbalance is not the consequence of residual tidal fluxes of water, because contrary to $\mathrm{DBC}$, there was more water flowing into than out of the marsh. A residual tidal flux of water is commonly observed in single-tidal cycles but when the residual tidal water fluxes are averaged over a larger number of tidal cycles, this asymmetry disappears. The tidal creek drains an area of 
$\sim 0.8 \mathrm{~km}^{2}$ upstream of the sampling station. When the residual tidal fluxes of DBC are normalized to this area, the runoff is $-3.7 \times 10^{3}$ moles carbon $\mathrm{km}^{-2}$. This estimate represents a snapshot of a single tidal cycle, and may not be representative of long-term fluxes. Storm surges and neap tides may behave differently, and seasonal fluctuations may also occur. Because a spring tide situation was studied, our estimate must be considered as an upper limit that is perhaps only surpassed by extreme storm surges. The black carbon production rate during fires in salt marshes is unknown. Tropical grassland fires produce $\sim 7 \times 10^{4}$ moles black carbon $\mathrm{km}^{-2}$ (Forbes et al. 2006). Consequently, it would require $\sim 20$ tidal cycles similar to the one we studied to remove all black carbon produced during one fire event in the marsh system. Because the last reported fire event occurred $3 \mathrm{yr}$ before our study, deposition of soilderived black carbon particles from the riverine catchment area during past storm surges is likely an additional source of black carbon in the marsh. Dissolution and subsequent lateral transport to the oceans appear to be important removal mechanisms for black carbon in soils. Our study provides a snapshot in time and space, but it clearly shows that tidal pumping and groundwater discharge cannot be ignored in assessing the continental runoff of DBC.

\section{Acknowledgments}

We thank the research coordinator of the Apalachicola National Estuarine Research Reserve, L. Edmiston, his team, and M. Laschet for helpful discussions and extraordinary support in the field. We appreciate the assistance of Y. Wang and Y. Wu with stable isotope analysis at the National High Magnetic Field Laboratory. We also thank the crew of the R/V Seminole (Florida State University) for support in the field. We thank Associate Editor P. Hernes and three anonymous reviewers for their constructive comments on the manuscript. This study was supported by the National Science Foundation (Ocean Sciences 726754 and Ocean Sciences 536431).

\section{References}

Abiven, S., P. Hengartner, M. P. W. Schneider, N. Singh, and M. W. I. Schmidt. 2011. Pyrogenic carbon soluble fraction is larger and more aromatic in aged charcoal than in fresh charcoal. Soil Biol. Biochem. 43: 1615-1617, doi:10.1016/ j.soilbio.2011.03.027

Alexis, M. A., AND others. 2007. Fire impact on C and N losses and charcoal production in a scrub oak ecosystem. Biogeochemistry 82: 201-216, doi:10.1007/s10533-006-9063-1

Boss, E., AND others. 2009. Comparison of inherent optical properties as a surrogate for particulate matter concentration in coastal waters. Limnol. Oceanogr.: Methods 7: 803-810, doi:10.4319/lom.2009.7.803

Brodowski, S., A. Rodionov, L. Haumaier, B. Glaser, and W. Amelung. 2005. Revised black carbon assessment using benzene polycarboxylic acids. Org. Geochem. 36: 1299-1310, doi:10.1016/j.orggeochem.2005.03.011

Cheng, C.-H., And J. Lehmann. 2009. Ageing of black carbon along a temperature gradient. Chemosphere 75: 1021-1027, doi:10.1016/j.chemosphere.2009.01.045

Cohen-Ofri, I., L. Weiner, E. Boaretto, G. Mintz, and S. WeIner. 2006. Modern and fossil charcoal: Aspects of structure and diagenesis. J. Archaeol. Sci. 33: 428-439, doi:10.1016/j.jas.2005.08.008
Dickens, A. F., Y. Gelinas, C. A. Masiello, S. G. Wakeham, And J. I. Hedges. 2004. Reburial of fossil organic carbon in marine sediments. Nature 427: 336-339, doi:10.1038/ nature02299

DitTmar, T. 2008. The molecular level determination of black carbon in marine dissolved organic matter. Org. Geochem. 39: 396-407, doi:10.1016/j.orggeochem.2008.01.015

- , N. Hertkorn, G. Kattner, and R. J. Lara. 2006. Mangroves, a major source of dissolved organic carbon to the oceans. Glob. Biogeochem. Cycles 20: GB1012, 1-7, doi:10.1029/2005GB002570

, AND B. P. KoCH. 2006. Thermogenic organic matter dissolved in the abyssal ocean. Mar. Chem. 102: 208-217, doi:10.1016/j.marchem.2006.04.003

- , N. Hertkorn, And G. Kattner. 2008. A simple and efficient method for the solid-phase extraction of dissolved organic matter (SPE-DOM) from seawater. Limnol. Oceanogr.: Methods 6: 230-235, doi:10.4319/lom.2008.6.230

, AND R. JAFFÉ. 2009. Tools for studying biogeochemical connectivity among tropical coastal ecosystems, p. 425-456. In I. Nagelkerken [ed.], Ecological interactions among tropical coastal ecosystems. Springer.

, R. J. Lara, And G. Kattner. 2001. River or mangrove? Tracing major organic matter sources in tropical Brazilian coastal waters. Mar. Chem. 73: 253-271, doi:10.1016/S03044203(00)00110-9

, AND J. PAeng. 2009. A heat-induced molecular signature in marine dissolved organic matter. Nat. Geosci. 2: 175-179, doi:10.1038/ngeo440

Druffel, E. R. M. 2004. Comments on the importance of black carbon in the global carbon cycle. Mar. Chem. 92: 197-200, doi:10.1016/j.marchem.2004.06.026

Edmiston, L. 2008. A river meets the bay - a characterization of the Apalachicola River and Bay system. Eastpoint (FL): Apalachicola National Estuarine Research Reserve. Available from http://www.dep.state.fl.us/coastal/downloads/management_ plans/A_River_Meets_the_Bay.pdf

Forbes, M. S., R. J. Raison, and J. O. SkJemstad. 2006. Formation, transformation and transport of black carbon (charcoal) in terrestrial and aquatic ecosystems. Sci. Total Environ. 370: 190-206, doi:10.1016/j.scitotenv.2006.06. 007

Glaser, B., L. Haumaier, G. Guggenberger, and W. Zech. 1998. Black carbon in soils: The use of benzenecarboxylic acids as specific markers. Org. Geochem. 29: 811-819, doi:10.1016/S0146-6380(98)00194-6

GugGenberger, G., AND OTHERs. 2008. Storage and mobility of black carbon in permafrost soils of the forest tundra ecotone in Northern Siberia. Glob. Change Biol. 14: 1367-1381, doi:10.1111/j.1365-2486.2008.01568.x

Hammes, K., AND others. 2007. Comparison of quantification methods to measure fire-derived (black/elemental) carbon in soils and sediments using reference materials from soil, water, sediment and the atmosphere. Glob. Biogeochem. Cycles 21: GB3016, doi:10.1029/2006GB002914

Hockaday, W. C., A. M. Grannas, S. Kim, and P. G. Hatcher. 2006. Direct molecular evidence for the degradation and mobility of black carbon in soils from ultrahigh-resolution mass spectral analysis of dissolved organic matter from a fireimpacted forest soil. Org. Geochem. 37: 501-510, doi:10.1016/ j.orggeochem.2005.11.003

, - AND - 2007. The transformation and mobility of charcoal in a fire-impacted watershed. Geochim. Cosmochim. Acta 71: 3432-3445, doi:10.1016/ j.gca.2007.02.023 
Kawamura, K., A. Okuwaki, T. V. Verheyen, and G. J. Peryy. 2006. Separation of aromatic carboxylic acids using quaternary ammonium salts on reversed-phase HPLC. 2. Application for the analysis of Loy Yang coal oxidation products. Separ. Sci. Technol. 41: 723-732, doi:10.1080/01496390500527985

Keiluweit, M., P. S. Nico, M. G. Johnson, and M. Kleber. 2010. Dynamic molecular structure of plant biomass-derived black carbon (biochar). Environ. Sci. Technol. 44: 1247-1253, doi:10.1021/es9031419

Kim, S., L. A. Kaplan, R. Benner, and P. G. Hatcher. 2004. Hydrogen-deficient molecules in natural riverine water samples - evidence for the existence of black carbon in DOM. Mar. Chem. 92: 225-234, doi:10.1016/j.marchem.2004.06.042

Kuo, L.-J., B. E. Herbert, and P. Louchouarn. 2008. Can levoglucosan be used to characterize and quantify char/ charcoal black carbon in environmental media? Org. Geochem. 39: 1466-1478, doi:10.1016/j.orggeochem.2008.04.026

Lehmann, J., J. Gaunt, And M. Rondon. 2006. Bio-char sequestration in terrestrial ecosystems - a review. Mitigation and Adaptation Strategies for Global Change 11: 403-427, doi:10.1007/s11027-005-9006-5

Major, J., J. Lehmann, M. Rondon, and C. Goodale. 2010. Fate of soil-applied black carbon: Downward migration, leaching and soil respiration. Glob. Change Biol. 16: 1366-1379, doi:10.1111/j.1365-2486.2009.02044.X

Mannino, A., AND H. R. Harvey. 2004. Black carbon in estuarine and coastal dissolved organic matter. Limnol. Oceanogr. 49: 735-740, doi:10.4319/1o.2004.49.3.0735
Masiello, C. A. 2004. New directions in black carbon organic geochemistry. Mar. Chem. 92: 201-213, doi:10.1016/ j.marchem.2004.06.043

—, And E. R. M. Druffel. 1998. Black carbon in deep-sea sediments. Nature 280: 1911-1913.

Moran, M., L. Pomeroy, E. Sheppard, L. Atkinson, and R. Hodson. 1991. Distribution of terrestrially derived dissolved organic matter on the southeastern U.S. continental shelf. Limnol. Oceanogr. 36: 1134-1149, doi:10.4319/lo.1991.36.6.1134

Saraceno, J. F., B. A. Pellerin, B. D. Downing, E. Boss, P. A M. Bachand, and B. A. Bergamaschi. 2009. High-frequency in situ optical measurements during a storm event: Assessing relationships between dissolved organic matter, sediment concentrations, and hydrologic processes. J. Geophys. Res. 114: G00F09, 1-11, doi:10.1029/2009JG000989

Schneider, M. P. W., M. Hilf, U. F. Vogt, and M. W. I. Schmidt. 2010. The benzene polycarboxylic acid (BPCA) pattern of wood pyrolyzed between $200^{\circ} \mathrm{C}$ and $1000^{\circ} \mathrm{C}$. Org. Geochem. 41: 1082-1088, doi:10.1016/j.orggeochem.2010.07.001

ZiMMERMAN, A. 2010. Abiotic and microbial oxidation of laboratory-produced black carbon (biochar). Environ. Sci. Technol. 44: 1295-1301, doi:10.1021/es903140c

Associate editor: Peter Hernes

Received: 04 November 2011 Accepted: 27 February 2012 Amended: 13 April 2012 